\title{
PERAN PENGAWASAN DALAM OPERASIONAL KOPERASI KONSUMEN YAYASAN PUSAKA RAUDHATUL IRFAN DESA KUTAWARGI KEC. RAWAMERTA KAB. KARAWANG
}

\author{
Sungkono \\ Fakultas Ekonoi dan Bisnis \\ Universitas Buana Perjuangan Karawang \\ sungkono@ubpkarawang.ac.id
}

\begin{abstract}
Abstrak
Perkembangan koperasi di Indonesia dapat dikatakan timbul teggelam, pada saatnya maju namu kadang menjadi mengalami kemunduran karena lemahnya Pengawan. Pada kondisi ini, penting untuk memberikan edukasi kepada segenap unsur yang menangani koperasi tersebut. Pengabdi merasa perlu utnuk memberikan masukankepada Pengurus khusunya kepada Pengawas Koerasi yaitu tentang Peran Pengawasan dalam Operasional Koperasi Konsumen Yayasan Pusaka Raudhatul Irfan Desa Kutawargi Kec. Rawamerta Kab. Karawang

Kergiatan pengabdian kepada masyarakat secara daring (online) selama satu hari ( 7 jam ) dapat disimpulkan bahwa: (a). Secara umum para pihak yang berkepentingan pada Koperasi Konsumen Yayasan Pusaka Raudhatul Irfan Desa Kutawargi Kecamatan Rawamerta Kabupaten Karawang menyadari masih kurangnya sistem pengawasan; (b). Peran kepengawasan pada Koperasi Konsumen Yayasan Pusaka Raudhatul Irfan Desa Kutawargi Kecamatan Rawamerta Kabupaten Karawang belum berjalan secara optimal; (c). Tingkat kepercayaan terhadap fungsi kepengawasan yang dilakukan masih rendah, oleh karena itu semua setuju untuk dilakukan sistem aplikasi
\end{abstract}

Kata kunci : Pengawas, Amanah, Maju. 


\section{PENDAHULUAN}

Pengelolaan usaha bagi suatu organisasi/perusahaan adalah penting, karena dengan pengelolaan penggunaan bahan baku yang baik maka organisasi/perusahaan tersebut dapat melaksanakan kegiatannya dengan lancar efektif dan efisien, serta peningkatan kinerja.

Koperasi, adalah salah satu lembaga keuangan non bank yang dalam hal ini tidak terlepas dari pengelolaan dengan baik. Lembaga ini juga tidak dapat mengabaikan kepercayaan baik dari internal koperasi itu sendiri (anggota) maupun dari pihak luar seperti bank, mitra usaha maupun masyarakat pada umumnya. Berdasarkan data empiris, tidak sedikit koperasi yang semula dapat tumbuh berkembang dengan baik, namun pada akhirnya mengalami gulung tikar karena salah satu penyebabnya adalah kurang memperhatikan terhadap pengelolaan usahanya dengan baik.

Oleh karena itu, melalui program pengabdian kepada masyarakat sebagai bagian dari Tri Dharma Perguruan Tinggi, saya selaku dosen pada Universitas Buana Perjuangan Karawang merasa perlu untuk memberikan masukan tentang bagaimana pengelolaan usahanya yang baik kepada Koperasi Konsumen Yayasan Pusaka Raudhatul Irfan. Hal ini penting, karena jangan sampai koperasi sebagai salah satu soko guru perekonomian, menjadi sesuatu seperti tertelan bumi, semakin lama semakin tidak eksis di masyarakat.

Mengingat sekarang masih dalam kondisi pandemic covid-19, maka pelaksanaan pengabdian masyarakat ini dilakukan dengan secara daring, yang dikuti dari tiga unsur, yaitu : dosen; mahasiswa Fakultas Ekonomi dan Bisnis Universitas Buana Perjuangan Karawang; dan segenap unsur pengurus Koperasi Konsumen Yayasan Pusaka Raudhatul Irfan. Adapun tema pengabdian adalah : “ Peran Pengawasan dalam Operasional Koperasi Konsumen Yayasan Pusaka Raudhatul Irfan Desa Kutawargi Kec. Rawamerta Kab. Karawang ". Jumlah peserta, terdiri dari : dosen = 32 orang; mahasiswa $=8$ orang; dan unsur pengurus koperasi $=10$ orang. Melalui tema ini, masingmasing dosen fokus pada bidangnya, sehingga berbagai masukan dapat diberikan kepada pihak Koperasi, diharapkan dapat bermanfaat untuk diaplikasikan bagi koperasi tersebut dan kepada masysrakat pada umumnya 


\section{METODE}

Kegiatan pengabdian masyarakat kepada Koperasi Konsumen Yayasan Pusaka Raudhatul Irfan Desa Kutawargi Kecamatan Rawamerta Kabupaten Karawang ini dilaksanakan yang telah disepakati dan di setujui ketiga unsur yang pelaksanaan kegiatannya dengan metode daring (online) yang dilaksanakan hanya selama 1 hari mulai jam 09.00 sampai dengan 16.00. yang elaksanaan kegiatan berupa penyuluhan dengan materi penyuluhan sesuai kebutuhan koperasi.

\section{HASIL DAN PEMBAHASAN}

1. Hasil

Kergiatan pengabdian secara daring dapat disimpulkan :

a. Secara umum para pihak yang berkepentingan pada Koperasi Konsumen Yayasan Pusaka Raudhatul Irfan Desa Kutawargi Kecamatan Rawamerta Kabupaten Karawang menyadari masih kurangnya sistem pengawasan.

b. Peran kepengawasan pada Koperasi Konsumen Yayasan Pusaka Raudhatul Irfan Desa Kutawargi Kecamatan Rawamerta Kabupaten Karawang belum berjalan secara optimal.

c. Tingkat kepercayaan terhadap fungsi kepengawasan yang dilakukan masih rendah, oleh karena itu semua setuju untuk dilakukan sistem aplikasi

\section{Pembahasan}

Berdasarkan hasil pengabdian, maka dapat diuraikan pembahasannya adalah :

a. Sistem Pengawasan yang dilaksanakan oleh Koperasi Konsumen Yayasan Pusaka Raudhatul Irfan Desa Kutawargi Kecamatan Rawamerta Kabupaten Karawang, masih bersifat manual yang tentu terdaapat kelemahan-kelemahannya, yang tentu masih membutuhkan perbaikan. .

b. Peran Pengawasannya yang dilaksanakan belum optimal pada Koperasi Konsumen Yayasan Pusaka Raudhatul Irfan Desa Kutawargi Kecamatan Rawamerta Kabupaten Karawang, besar kemungkinan dapat membuka peluang untuk terjadinya penyimpangan- penyimpangan.

c. Korelasi antar sistem dan peran pengawasan yang masih sederhana yang terjadi pada Koperasi Konsumen Yayasan Pusaka Raudhatul Irfan Desa Kutawargi Kecamatan Rawamerta Kabupaten Karawang, secara tidak langsung akan mendapatkan kepercayaan dari atau pemangku kepentingan masih rendah. 


\section{KESIMPULAN DAN SARAN}

\section{Kesimpulan}

Hasil Pengabdian kepada masyarakat yang dilaksanakan tentang Peran Pengawasan dalam Operasional Koperasi Konsumen Yayasan Pusaka Raudhatul Irfan Desa Kutawargi Kecamatan . Rawamerta Kabupaten Karawang., adalah :

a. Sistem Pengawasan pada Koperasi Konsumen Yayasan Pusaka Raudhatul Irfan Desa Kutawargi Kecamatan Rawamerta Kabupaten Karawang masih kurang.

b. Peran kepengawasan pada Koperasi Konsumen Yayasan Pusaka Raudhatul Irfan Desa Kutawargi Kecamatan Rawamerta Kabupaten Karawang belum berjalan secara optimal.

c. Kepercayaan anggota terhadap fungsi kepengawasan yang dilakukan masih rendah, dan perlu adanya sistem yang lebih baik lagi

\section{Saran}

Berdasarkan kesimpulan sebagaimana tersebut di atas, maka kepada Pengawas Koperasi Konsumen Yayasan Pusaka Raudhatul Irfan Desa Kutawargi Kecamatan . Rawamerta Kabupaten dapat disarankan beberapa hal sebagai berikut :

a. Khusus kepa Pengawas Konsumen Yayasan Pusaka Raudhatul Irfan Desa Kutawargi Kecamatan . Rawamerta Kabupaten Karawang, agar dapat memperbaiki sistem pengawasannya, sehingga kinerja koperasi menjadi lebih baik

b. Pengawas sebaiknya meningkatkan perannya, dengan cara melakukan audit bukan hanya setahun sekali, akan tetapi triwulan sekali sehingga kalau ada kesalahan dapat diperbaiki lebih awal.

c. Untuk meningkatkan sistem dan peran kepengawasan, sebaiknya menggunakan sisitem baru yaitu dengan aplikasi sistem secara online. 


\section{DAFTAR PUSTAKA}

\section{Buku}

M.D. Sagimun, 2000, Koperasi Indonesia, Jakarta, P.T. Midas Surya Grafindo

Ninik Widiyanti dan Sunindhia, 2009, Koperasi dan Perekonomian Indonesia, Jakarta, Rineka Cipta

Ronny Hanitijo Soemitro, 1994, Metode Penelitian Hukum dan Jurimetri, Jakarta, Ghalia Indonesia

Rudianto, 2010, Akuntansi Koperasi, Jakarta, Erlangga

Undang- Undang Koperasi Nomor 25 Tahun 1992

\section{Artikel/Jurnal:}

Aji Basuki Rohmat. 2015. Analisis Penerapan Prinsip-Prinsip Koperasi, Jurnal Pembaharuan Hukum Volume. 2(1): 140.

Endi Sarwoko. 2009. Analisis Peranan Koperasi Dalam Upaya Pengembangan UMKM Di Kabupaten Magelang. Jurnal Ekonomi Modernisasi 5 (3): 172188.

Heriyono. 2012. Peran Koperasi Dalam Pengembangan Perekonomian Rakyat JURNAL EKONOMI ISSN: 2302-7169 1(1): 40 


\section{LAMPIRAN}

Berikut adalah bukti empirik hasil pelaksanaan kegiatan pengabdian masyarakat tentang peran kepengawasan pada Koperasi Konsumen Yayasan Pusaka Raudhatul Irfan Desa Kutawargi Kecamatan Rawamerta Kabupaten Karawang :
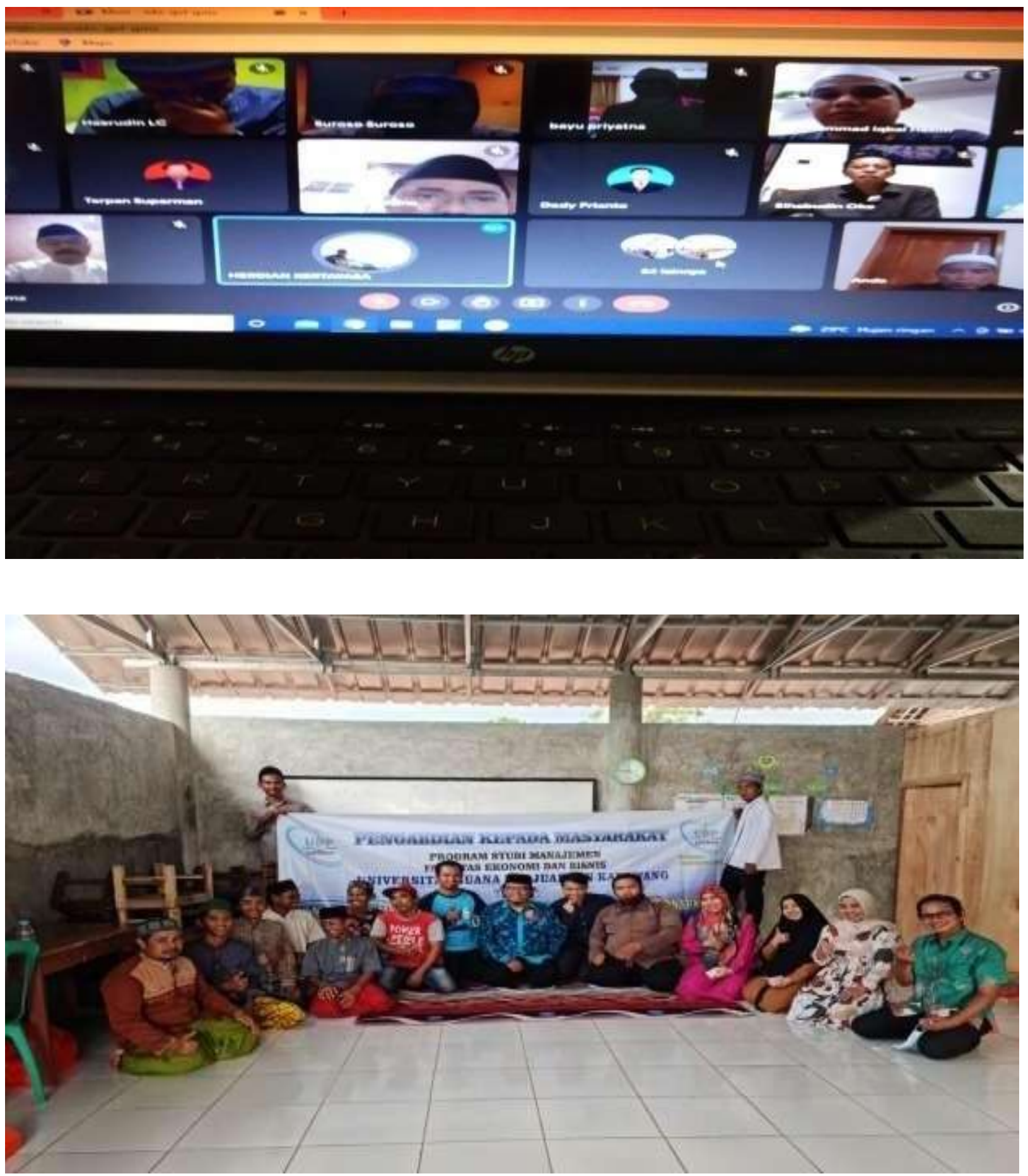